\title{
Research on Torque Ratio Based on the Steering Wheel Torque Characteristic for Steer-by-Wire System
}

\author{
Yandong Han, ${ }^{1}$ Lei He, ${ }^{1}$ Xiang Wang, ${ }^{2}$ and Changfu Zong ${ }^{1}$ \\ ${ }^{1}$ State Key Laboratory of Automotive Simulation and Control, Jilin University, Changchun 130022, China \\ ${ }^{2}$ Automobile Engineering Institute, Guangzhou Automobile Group Co., Ltd. Guangzhou 511434, China \\ Correspondence should be addressed to Lei He; jlu_helei@jlu.edu.cn
}

Received 25 April 2014; Accepted 22 June 2014; Published 6 July 2014

Academic Editor: Hamid R. Karimi

Copyright (c) 2014 Yandong Han et al. This is an open access article distributed under the Creative Commons Attribution License, which permits unrestricted use, distribution, and reproduction in any medium, provided the original work is properly cited.

\begin{abstract}
Steer-by-wire system can improve the performance of vehicle handling stability. Removing the mechanical linkages between the front wheels and the steering wheel leads to a key technique of force feedback for steer-by-wire system. In view of the characteristic of variable torque transmission ratio for steer-by-wire system, this paper proposes a method for designing torque ratio based on the steering wheel torque characteristic for steer-by-wire system. It converts the torque ratio design into equivalent assist torque design by analyzing their relationship. It achieves the torque ratio design at different conditions based on the negative equivalent assist torque characteristic curve. Simulations and vehicle experiments are conducted by the proposed method, and the results show that the design goal has been achieved and the steering wheel torque characteristic obtained is very similar to that of the reference car.
\end{abstract}

\section{Introduction}

Steer-by-wire (SBW) system removes the mechanical linkages between the steering wheel (SW) and the front wheels, which makes the transmission ratio of SBW system variable. The torque transmission ratio $\alpha$, namely, the ratio of the pinion torque and the SW torque, determines the SW torque characteristic. The simulation method of road feel is one of the key technologies for SBW system. A good simulation method of road feel can help to improve steering handiness at low speed and road feel at high speed and lead to a better handling stability and driving safety. For this reason, the study of road feel has drawn much attention. Im et al. utilized torque sensors to obtain the steering resistance between the front wheels and road and fed it back to the driver with a certain torque ratio [1]. A kind of road feel algorithm was proposed by utilizing the linear relationship between the electromagnetic torque and electric current of the steering motor to obtain the torque. Then the torque was fed back to the driver with a certain torque ratio [2-4]. A kind of virtual force feedback characteristic was also designed based on vehicle speed, steering angle, and other vehicle parameters in the conventional steering system $[5,6]$. Based on the analysis of the assist characteristic and the active damping control strategy of the EPS system, an integrated road feel algorithm was proposed [7]. Mehdizadeh et al. proposed the concept of virtual vehicle to provide the driver with a familiar force feedback [8]. And friction, stiffness, and damping compensation were also used to improve the performance of road feel control [9]. Sliding mode control was applied to the control of the steer-by-wire vehicles to obtain strong robustness [10].

The first two methods focus on the establishment of steering resistance observers and ignore the effects of the torque ratio, so they can only reflect the SW torque characteristic partly. The third method can only provide a virtual road feeling and not reflect the real adhesion state of the wheels and road. The fourth and fifth methods are to be further perfected. The last two methods just stress discussing the control algorithms. It is obvious that most current researches focus on how to obtain the steering resistance and ignore the influences of the torque ratio on handling stability because of the structure restriction of SBW system. A torque ratio design method based on the SW torque characteristic for SBW system is proposed and verified in this paper. 


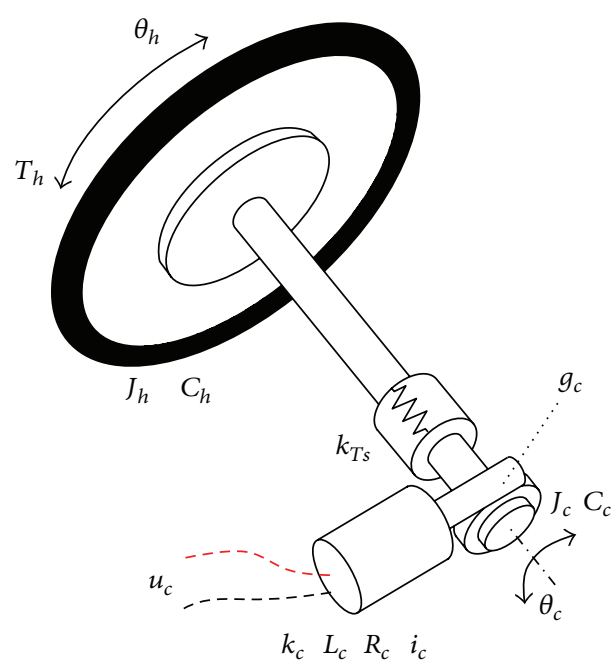

FIgURE 1: Structure of the SW block.

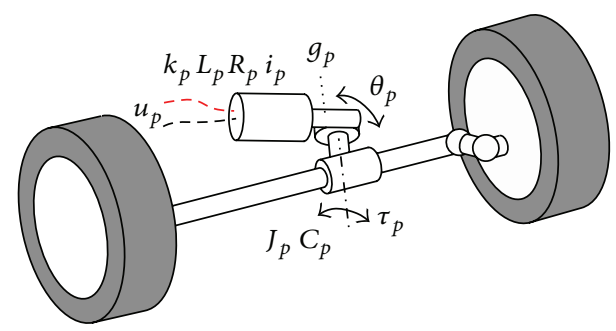

FIGURE 2: Structure of the steering executive block.

\section{Materials and Methods}

\subsection{SBW System and Vehicle Model}

2.1.1. SBW System Model. The SBW system consists of two blocks: the SW block and the steering executive block. Since the torsional stiffness of the torque sensor is low relatively, the SW block can be divided into two parts: the SW assembly and the steering column assembly. The SW assembly consists of the SW and part of the column that is the district between the SW and the torque sensor. The steering column assembly consists of the remaining part of the steering column, road feel motor, and its reducer. The structure of the SW block is shown in Figure 1.

Each of the two assemblies has one rotational degree, the angle of the SW, and the angle of the steering column. The dynamical formulas of the SW block are as follows:

$$
\begin{gathered}
T_{h}-T_{s}=J_{h} \ddot{\theta}_{h}+C_{h} \dot{\theta}_{h}, \\
T_{s}=k_{T s}\left(\theta_{h}-\theta_{c}\right), \\
T_{s}-g_{c} k_{c} i_{c}=J_{c} \ddot{\theta}_{c}+C_{c} \dot{\theta}_{c}, \\
u_{c}=g_{c} k_{c} \dot{\theta}_{c}+L_{c} \dot{i}_{c}+R_{c} i_{c},
\end{gathered}
$$

where $\theta_{h}$ and $\theta_{c}$ are the angle of the SW and the steering column, respectively. $k_{T s}$ is the stiffness of the torque sensor. $T_{h}$ is the torque of the driver input and $T_{s}$ is the measured
TABLE 1: Parameters of SW block.

\begin{tabular}{lc}
\hline Parameters & Values \\
\hline Stiffness of torque sensor $k_{T_{s}}$ & $176 \mathrm{Nm} / \mathrm{rad}$ \\
Equivalent moment of inertia $J_{h}$ & $0.022 \mathrm{kgm}^{2}$ \\
Equivalent moment of inertia $J_{c}$ & $0.116 \mathrm{kgm}^{2}$ \\
Equivalent damping coefficient $C_{h}$ & $0.02 \mathrm{Nms} / \mathrm{rad}$ \\
Equivalent damping coefficient $C_{c}$ & $0.13 \mathrm{Nms} / \mathrm{rad}$ \\
Reduction ratio of worm and gear $g_{c}$ & 15 \\
\hline
\end{tabular}

TABLE 2: Parameters of steering executive block.

\begin{tabular}{lc}
\hline Parameters & Values \\
\hline $\begin{array}{l}\text { Equivalent friction torque } T_{\text {friction }-p} \\
\text { (column hysteresis in Carsim) }\end{array}$ & $2.1 \mathrm{Nm}$ \\
$\begin{array}{l}\text { Equivalent damping coefficientat rack } \\
\text { (front steering damping in Carsim) }\end{array}$ & $2.1 \mathrm{Ns} / \mathrm{mm}$ \\
$\begin{array}{l}\text { Equivalent moment of inertia } J_{p} \\
\text { (system inertia in Carsim) }\end{array}$ & $0.12 \mathrm{kgm}^{2}$ \\
$\begin{array}{l}\text { Ratio of steering gear } \\
(\mathrm{C} \text { factors in Carsim) }\end{array}$ & $49.93 \mathrm{~mm} / \mathrm{rev}$ \\
Reduction ratio of worm and gear $g_{p}$ & 15 \\
\hline
\end{tabular}

torque by torque sensor. $J_{h}$ and $J_{c}$ are the equivalent moment of inertia of the two parts at steering column, respectively. $C_{h}$ and $C_{c}$ are the equivalent damping coefficient of the two parts at steering column, respectively. $g_{c}$ is the reduction ratio of worm and gear reducer. $u_{c}, k_{c}, L_{c}, R_{c}$, and $i_{c}$ are the voltage, the back EMF constant (torque constant), the inductance, the resistance, and the current of the road feel motor, respectively.

The structure of the steering executive block is shown in Figure 2. The dynamical formulas of steering executive block are as follows:

$$
\begin{aligned}
& g_{p} k_{p} i_{p}-\tau_{p}=J_{p} \ddot{\theta}_{p}+C_{p} \dot{\theta}_{p}, \\
& u_{p}=g_{p} k_{p} \dot{\theta}_{p}+L_{p} \dot{i}_{p}+R_{p} i_{p},
\end{aligned}
$$

where $\theta_{p}$ is the angle of the pinion. $\tau_{p}$ is the equivalent resistance between the front wheels and the road at the pinion shaft. $J_{p}$ and $C_{p}$ are the equivalent moment of inertia and the equivalent damping coefficient of the block at the pinion shaft, respectively. $g_{p}$ is the reduction ratio of worm and gear reducer. $u_{p}, k_{p}, L_{p}, R_{p}$, and $i_{p}$ are the voltage, the back EMF constant (torque constant), the inductance, the resistance, and the current of the steering motor, respectively.

2.1.2. Vehicle Model. The SBW vehicle tests are conducted to verify assist torque characteristic in parking condition. The SBW test vehicle, as shown in Figure 3, is refitted from a domestic A-class car. The electrical parameter values of two blocks are obtained by the least-squares method, as discussed elsewhere [11]. The mechanical parameter values of two blocks are shown in Tables 1 and 2. The experiment approach of parameter identification is discussed by Wang in detail in [12].

A Carsim vehicle model is used to verify assist torque characteristic in the on-center, linear, and nonlinear region 
TABLE 3: On-center evaluation indices of SW torque characteristic.

\begin{tabular}{|c|c|c|}
\hline \multicolumn{2}{|c|}{ Performance } & \multirow{2}{*}{$\begin{array}{l}\text { Evaluation indices } \\
\text { Lateral acceleration at } \\
0 \mathrm{Nm}\end{array}$} \\
\hline \multirow[t]{3}{*}{ Hysteresis } & $\begin{array}{l}\text { Lateral } \\
\text { acceleration-SW } \\
\text { torque }\end{array}$ & \\
\hline & \multirow{2}{*}{$\begin{array}{l}\text { SW angle-SW } \\
\text { torque }\end{array}$} & Steering hysteresis \\
\hline & & Steering fiction torque \\
\hline Sensitivity & SW torque & $\begin{array}{l}\text { Average steering } \\
\text { stiffness }\end{array}$ \\
\hline \multirow{3}{*}{ Road feel } & \multirow[t]{2}{*}{ Torque gradient } & $\begin{array}{l}\text { Steering torque } \\
\text { gradient at } 0 \mathrm{~g}\end{array}$ \\
\hline & & $\begin{array}{l}\text { Steering torque } \\
\text { gradient at } 0.1 \mathrm{~g}\end{array}$ \\
\hline & Torque & SW torque at $0.1 \mathrm{~g}$ \\
\hline
\end{tabular}

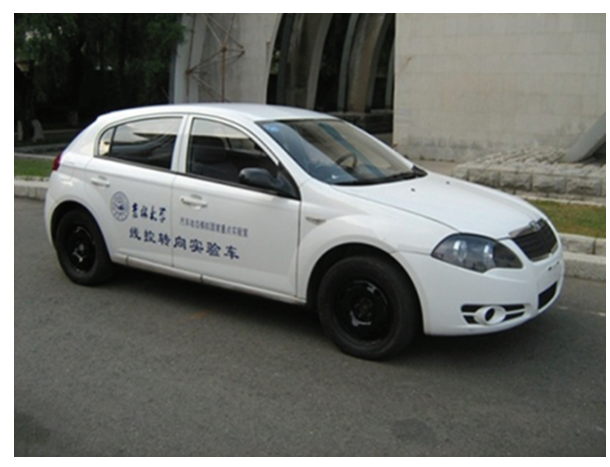

FIgURE 3: The SBW test vehicle.

and limit working conditions. The parameters, assembly, and size of the Carsim model are all very similar to those of the SBW test vehicle. SBW system model is built by MATLAB/Simulink. The vehicle dynamics simulations are achieved by the cosimulation of Carsim and Simulink. SBW system employs the bilateral control method of torque drive/angle feedback [13].

\subsection{Design Basis of Torque Ratio}

2.2.1. Objective Evaluation Indices of the SW Torque Characteristic. According to the research on objective evaluation system of handling stability, the SW torque characteristic is in the category of maneuverability and can be divided into three factors: the on-center torque characteristic, the steering effort characteristic for keeping a given control, and the SW torque level in parking condition [14]. Oncenter torque characteristic describes the variation of the SW torque, while the SW angle or lateral acceleration alters under the condition of high vehicle speed and small lateral acceleration. By analyzing and filtering the evaluation indices, the streamlined evaluation indices are shown in Table 3 [15]. The test method refers to [16].

Steering effort characteristic for keeping a given control describes the variation of the SW torque, while the speed and lateral acceleration alter under the condition of medium or large lateral acceleration. The SW torque should increase with the increase of the speed and lateral acceleration. When the tires are close to the limit of adhesion, the SW torque should be decreased to help driver acquire the adhesion state of the tires. When the SW torque reaches the maximum value, the steering maneuverability and comfort should not be affected. The improper maximum SW torque leads to heavy steering and hinders the driver from turning the SW quickly. Over the entire range of lateral acceleration, the SW torque should be able to reflect the lateral acceleration and the adhesion state between tires and road truthfully. Relevant researches show that the SW torque desired by drivers is affected by gender, age, and ethnic factors [17-19]. So this paper designs the torque ratio based on the steering effort preference.

SW torque level in parking condition describes the SW torque, while steering in situ or at low speed and the SW closed to the limit position. The SW torque level is assessed by the indices of the steering effort at $70 \%$ of the entire steering angle range under the condition of steering in situ. It is reasonable that the torque is no more than $5 \mathrm{Nm}$ for the power steering system in general, which applies to SBW system as well. The SW work level is assessed by the homonymic indices in steering handiness test. The test method refers to [20]. In addition, the SW torque delivered to the driver should not decrease with the increase of the SW angle when the SW is close to limit position. Otherwise it will generate a steering impact to the front wheels, which is not what we want.

2.2.2. Design Basis of Torque Ratio. If we can transplant the assist characteristic of power steering system to SBW system, the SW torque characteristic and yaw response of the SBW vehicle will be very similar to the vehicle equipped with power steering system. Considering the advantages of SBW system, the ratio designed should not only enable the performance SBW vehicle to match with the vehicle equipped with power steering system but also be adjustable to meet different groups of people and diverse working conditions. Summarizing relevant researches and test results, the relative ideal SW torque characteristic should meet the following requirements.

(1) The SW torque should increase in proportion to the increase of speed and lateral acceleration in steady steering condition. The torque should increase significantly with the increase of lateral acceleration in linear region and not significantly in nonlinear region. When the tires are close to the limit of adhesion, the torque should be declined with the increase of lateral acceleration [21, 22].

(2) The design of the on-center SW torque characteristic can refer to the parameters in Table 4 . The parameters are the relevant on-center objective evaluation indices of one domestic car, which is called the reference car hereinafter.

(3) The steering effort at $70 \%$ of the entire steering angle range should be less than $4.5 \mathrm{Nm}$ in parking condition. When the SW is close to the limit position, the SW torque should increase smoothly, which can become a reminder to the driver. 
TABLE 4: On-center evaluation indices of the reference car.

\begin{tabular}{lc}
\hline Evaluation & Value \\
\hline Lateral acceleration at $0 \mathrm{Nm}(\mathrm{g})$ & 0.042 \\
Steering hysteresis $(\mathrm{deg})$ & 5.32 \\
Steering fiction torque $(\mathrm{Nm})$ & 1.64 \\
Average steering stiffness $(\mathrm{Nm} / \mathrm{deg})$ & 0.36 \\
Steering torque gradient at $0 \mathrm{~g}(\mathrm{Nm} / \mathrm{g})$ & 32.0 \\
Steering torque gradient at $0.1 \mathrm{~g}(\mathrm{Nm} / \mathrm{g})$ & 9.06 \\
SW torque at $0.1 \mathrm{~g}(\mathrm{Nm})$ & 2.75 \\
\hline
\end{tabular}

2.3. Conversion of Torque Ratio into Equivalent Assist Torque. The above objective evaluation indices provide a reasonable SW torque characteristic and we can design a relatively ideal torque ratio for SBW system by analyzing the relationship between the ratio and the indices. The damping, inertia, and friction of SBW system increase by about $200 \%-370 \%$ because of the two motors. That will cause great impacts on vehicle performance. So the SBW control system should compensate for these mechanical parameters. The compensation method should be adjusted and can improve vehicle performance. The specific compensation methods refer to [12]. Ignoring the effects of damping and inertia on the SW torque characteristic and considering the equivalent friction of steering executive block at the pinion, (2) can be rewritten as

$$
T_{p}-\tau_{p}=J_{p} \ddot{\theta}_{p}+C_{p} \dot{\theta}_{p}+\operatorname{sgn}\left(\dot{\theta}_{p}\right) T_{\text {friction_ } p},
$$

where $T_{\text {friction_p }}$ is the equivalent friction of steering block at the pinion shaft. $\tau_{p}$ is the resistance between the front wheels and road. $T_{p}$ is the control torque of steering motor and the specific control method is similar to that of EPS system [23, 24]. $T_{p}$ can be specifically expressed as

$$
T_{p}=T_{\alpha}+T_{J p}+T_{C p}+T_{f p},
$$

where $T_{\alpha}=\alpha T_{s}$ is the direct drive torque. $T_{J p}, T_{C p}$, and $T_{f p}$ are the compensation moment of inertia, damping, and fiction, respectively. The contents of the objective evaluation system are for the SW torque characteristic in steady state and quasi steady state. The damping and inertia of steering system, which greatly affects dynamic performance, need to be debugged and calibrated by the subjective evaluation. Therefore only considering the friction compensation and ignoring the impact of damping and inertia on the SW torque characteristic, (4) can be rewritten as

$$
\alpha T_{s}+T_{f p}=\tau_{p}+T_{\text {friction }_{-}}\left(\dot{\theta}_{p}\right) .
$$

Road feel intensity $E$, as shown in (7), which is the ratio of torque increment of the SW $d T_{h}$ and the output torque increment of steering gear $d F_{p}$, is used to measure the intensity of road feeling [25]:

$$
E=\frac{d T_{h}}{d F_{p}}
$$

Ignoring the friction and the compensation torque of the steering executive block, $T_{h}$ is approximately equal to $T_{s}$
TABLE 5: On-center evaluation indices of negative equivalent assist characteristic curve.

\begin{tabular}{lc}
\hline Evaluation indices & Value \\
\hline Lateral acceleration at $0 \mathrm{Nm}(\mathrm{g})$ & 0.019 \\
Steering hysteresis $(\mathrm{deg})$ & 4.69 \\
Steering fiction torque $(\mathrm{Nm})$ & 1.52 \\
Average steering stiffness $(\mathrm{Nm} / \mathrm{deg})$ & 0.32 \\
Steering torque gradient at $0 \mathrm{~g}(\mathrm{Nm} / \mathrm{g})$ & 33.5 \\
Steering torque gradient at $0.1 \mathrm{~g}(\mathrm{Nm} / \mathrm{g})$ & 9.31 \\
SW torque at $0.1 \mathrm{~g}(\mathrm{Nm})$ & 2.44 \\
\hline
\end{tabular}

under the condition of small SW angular speed and acceleration. So $E$ can be expressed as

$$
E=\frac{d T_{h}}{d F_{p}}=r_{p} \frac{d T_{h}}{d \tau_{p}}=r_{p} \frac{d T_{s}}{d \tau_{p}}=r_{p} \frac{1}{\alpha\left(T_{s}\right)},
$$

where $r_{p}$ is the radius of the pinion. Because $r_{p}$ is a constant gain, $1 / \alpha$ can be used to measure the intensity of road feeling. Referring to the design method of EPS system [23, 24], the relationship between equivalent assist torque $T_{\text {assis }}$ of EPS system and torque ratio $\alpha$ of SBW system can be expressed as

$$
\alpha=\frac{T_{\mathrm{assis}}+T_{s}}{T_{s}}
$$

Obviously, " $\alpha T_{s}$ ” can be replaced by " $T_{\text {assis }}+T_{s}$ ” and the torque ratio can be designed based on (9). So the study of torque ratio is replaced by the study of equivalent assist torque hereinafter.

\section{Results and Discussion}

Equivalent assist torque characteristic is not only related to the SW torque, but also varies with vehicle speed. To facilitate the calibration of SBW equivalent assist torque characteristic, a series of characteristic speed should be determined firstly. Then a series of characteristic curves, which show the relationship between equivalent assist torque and the SW torque at characteristic speed, should be designed. The curves at other speeds are designed by linear interpolation. The partition method of characteristic speed is not discussed here. The design method of equivalent assist torque characteristic is illustrated by designing the characteristic at $100 \mathrm{~km} / \mathrm{h}$. The curve in Figure 4 is negative equivalent to assist torque characteristic curve, which is proposed in [12] by Wang. It is obvious that the characteristic curve includes four factors: the on-center slope, the SW torque range corresponding to large curvature region, the SW torque in linear and nonlinear region, and the maximum equivalent assist torque. The on-center evaluation indices of the characteristic curve in Figure 4 are shown in Table 5. The torque ratio design method proposed is based on this curve. We can achieve the design goal by adjusting the characteristic curve.

3.1. Equivalent Assist Characteristic in Linear, Nonlinear, and Limit Region. The steering effort preference is summarized 


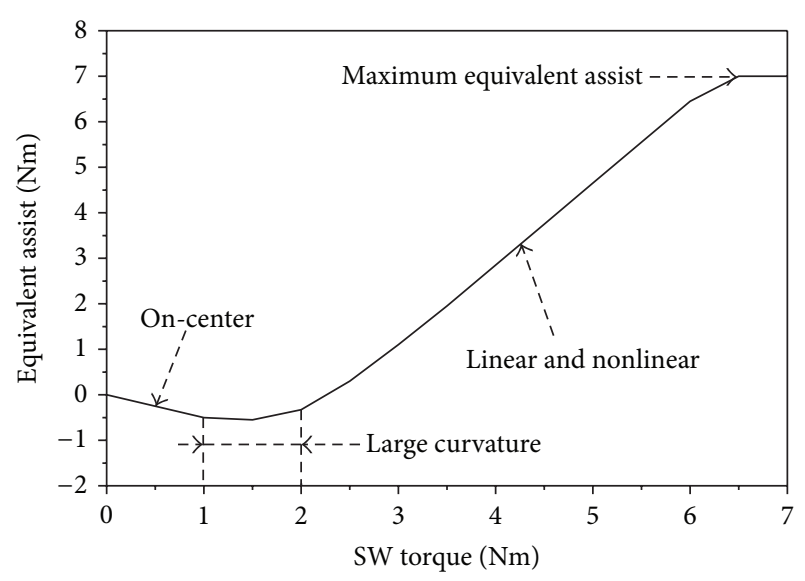

FIGURE 4: Negative equivalent assist characteristic curve.

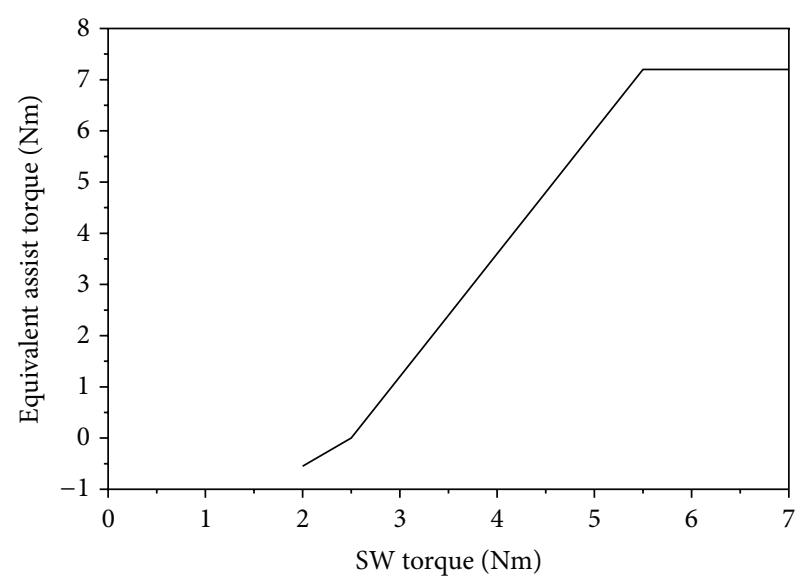

FIGURE 5: Equivalent assist characteristic in linear region at $100 \mathrm{~km} / \mathrm{h}$.

with VTI driving simulator in [17]. The steering effort preference of Chinese drivers by using ADSL driving simulator is summarized in [22]. Referring to the above research results and Table 3, the steering effort characteristic for keeping a given control in linear region is designed. The target SW torque at lateral acceleration of $0.1 \mathrm{~g}$ is $2.6 \mathrm{Nm}$ and at $0.3 \mathrm{~g}$ is $2.6 \mathrm{Nm}$. In the test the driver turns the SW at rotation speed of $360 \mathrm{deg} / \mathrm{min}$ until the lateral acceleration reaches $0.75 \mathrm{~g}$, while the vehicle speed is $100 \mathrm{~km} / \mathrm{h}$.

The characteristic curve in Figure 5, which results from adjusting the SW torque region from $2 \mathrm{Nm}$ to $4 \mathrm{Nm}$ of the curve in Figure 3, helps to achieve the design goals of the SW torque at lateral acceleration of $0.1 \mathrm{~g}$ and $0.3 \mathrm{~g}$, as shown in Figure 6. The test results show that when the SW torque is more than $2.5 \mathrm{Nm}$, there is a linear relationship between feedback torque and steering resistance at the lateral acceleration region from $0.1 \mathrm{~g}$ to $0.42 \mathrm{~g}$ and a nonlinear relation from $0.42 \mathrm{~g}$ to $0.65 \mathrm{~g}$. When the lateral acceleration is over $0.65 \mathrm{~g}$, feedback torque decreases a little. So the SW torque characteristic can reflect the steering resistance faithfully in linear, nonlinear, and limit region. The driver can feel the adhesion state and the lateral acceleration precisely.

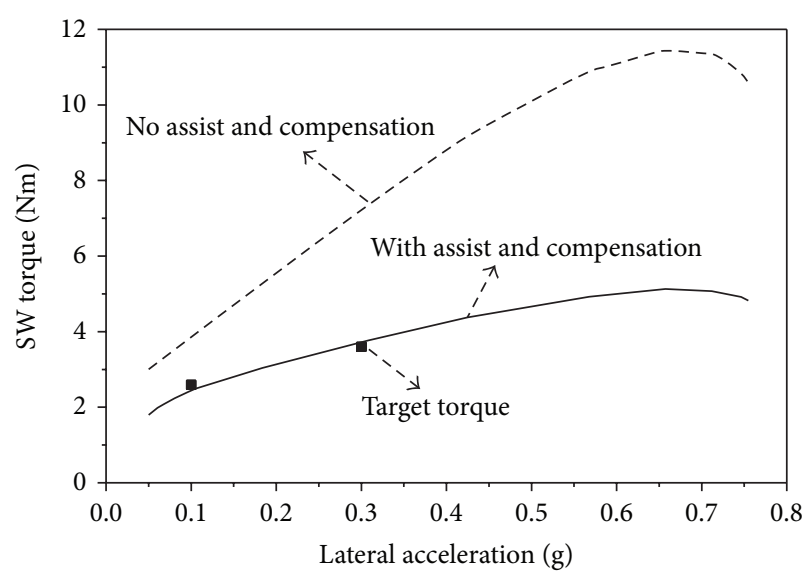

FIGURE 6: Steering effort characteristic for keeping a given control at $100 \mathrm{~km} / \mathrm{h}$.

3.2. On-Center Equivalent Assist Characteristic. Comparing the on-center evaluation indices in Tables 4 and 5, we can find the following.

(1) The hysteresis of lateral acceleration and the SW angle relative to the SW torque of the model are significantly lower than those of the reference car. On one hand it results from negative equivalent assist characteristic and friction compensation. On the other hand it results from the differences of hysteresis characteristic between a model and a car.

(2) Average steering stiffness and the SW torque gradient at lateral acceleration of $0 \mathrm{~g}$ of the model are close to those of the reference car. So these two indices will not be adjusted. It is found in the test that increasing the on-center slope of the equivalent assist characteristic curve can improve the characteristics.

(3) The SW torque and torque gradient of the model at lateral acceleration of $0.1 \mathrm{~g}$ has determined by the steering effort characteristic for keeping a given control shown in Figure 6.

(4) The SW torque level corresponding to the large curvature region of the equivalent power characteristic curve of the model should be consistent with that of the reference car. The torque specifically refers to the SW torque corresponding to the lateral acceleration region from 0 to $0.1 \mathrm{~g}$. The torque range of the reference car is from $1.01 \mathrm{Nm}$ (half of the steering friction torque) to $2.75 \mathrm{Nm}$ (the SW torque at lateral acceleration of $0.1 \mathrm{~g}$ ).

The last equivalent assist characteristic curve on-center and large curvature region is shown in Figure 7. The corresponding indices of the model and the reference car are shown in Table 6. By a targeted calibration, SBW vehicle model has a similar on-center road feel and the SW torque characteristic to the reference car. And the model has a smaller delay. In other words, the aligning performance of SBW vehicle model is better. 


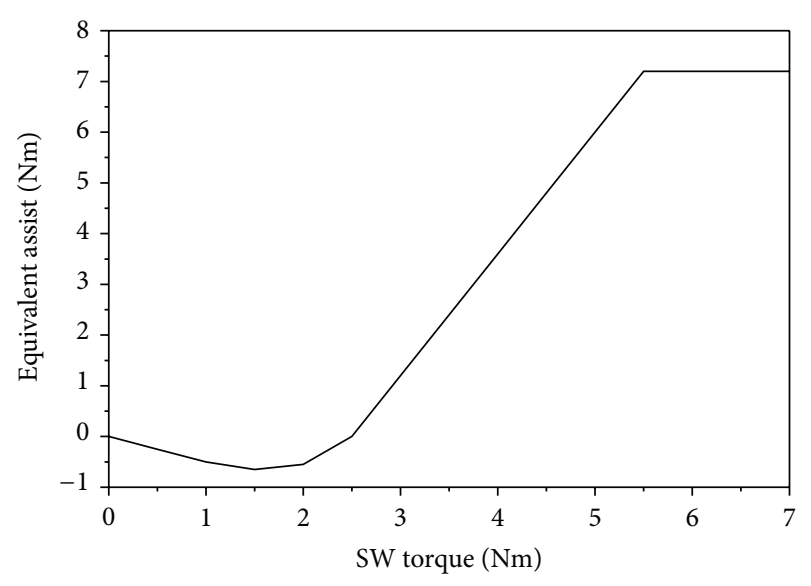

FIGURE 7: On-center equivalent assist characteristic at $100 \mathrm{~km} / \mathrm{h}$.

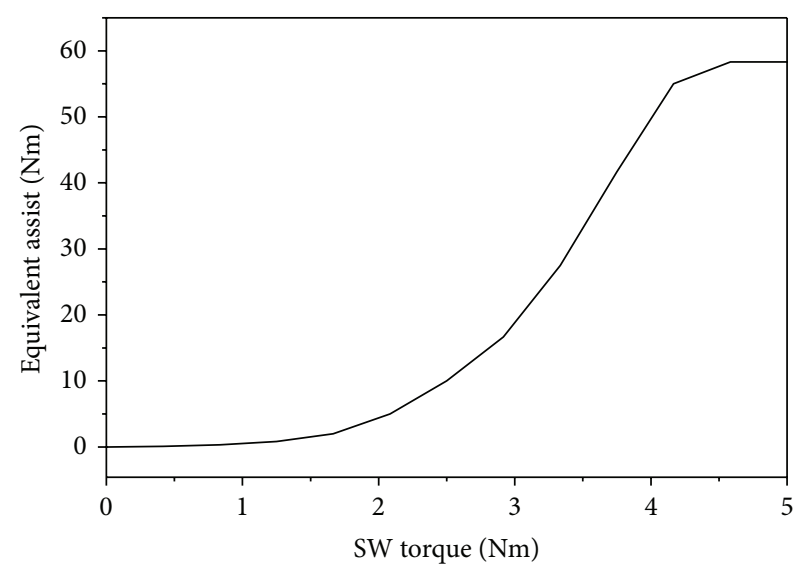

FIgURE 8: Equivalent assist characteristic at $0 \mathrm{~km} / \mathrm{h}$.

TABLE 6: On-center evaluation indices at $100 \mathrm{~km} / \mathrm{h}$.

\begin{tabular}{lcc}
\hline Evaluation indices & Reference car & model \\
\hline Lateral acceleration at $0 \mathrm{Nm}(\mathrm{g})$ & 0.042 & 0.021 \\
Steering hysteresis $(\mathrm{deg})$ & 5.32 & 4.98 \\
Steering fiction torque $(\mathrm{Nm})$ & 1.64 & 1.62 \\
Average steering stiffness $(\mathrm{Nm} / \mathrm{deg})$ & 0.36 & 0.29 \\
Steering torque gradient at $0 \mathrm{~g}(\mathrm{Nm} / \mathrm{g})$ & 32.0 & 33.7 \\
Steering torque gradient at $0.1 \mathrm{~g}(\mathrm{Nm} / \mathrm{g})$ & 9.06 & 8.73 \\
SW torque at $0.1 \mathrm{~g}(\mathrm{Nm})$ & 2.75 & 2.61 \\
\hline
\end{tabular}

3.3. Equivalent Assist Characteristic in Parking Condition. The test of steering in situ is conducted to verify the characteristic in parking condition. In the test the driver turns the SW at rotation speed of $10 \sim 15 \mathrm{r} / \mathrm{min}$ to the right limit position, then to the left limit position, and at last go to the right limit position, that is, one cycle. One test has two cycles and repeats the test three times [20]. The equivalent assist characteristic in parking condition is shown in Figure 8. The characteristic curve of the SW torque versus the SW angle is shown in Figure 9. The SW torque at 70 percent of the entire steering angle range is $3.73 \mathrm{Nm}$, which represents a good handiness.

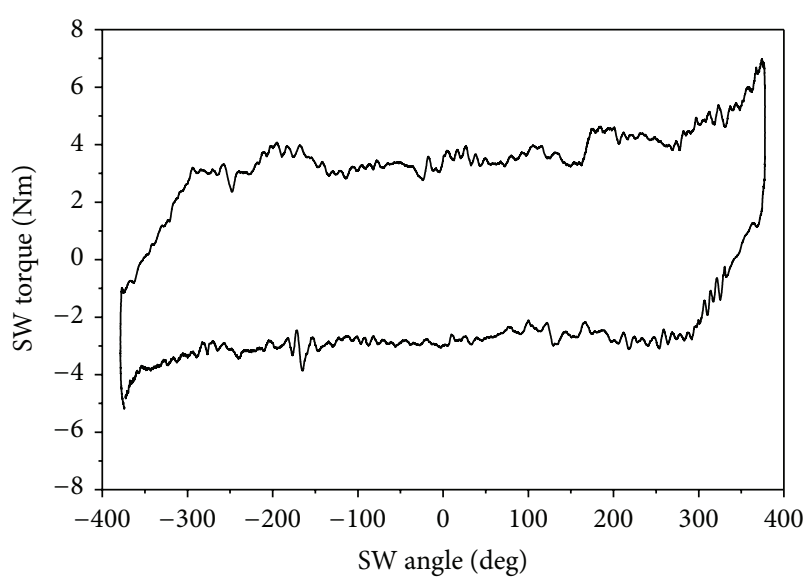

Figure 9: $\mathrm{SW}$ torque versus $\mathrm{SW}$ angle at $0 \mathrm{~km} / \mathrm{h}$.

\section{Conclusions}

A torque ratio design method based on the SW torque characteristic for SBW system is proposed. According to the classification of the handling evaluation indices, the SW torque characteristic can be divided into three factors: the oncenter torque characteristic, the steering effort characteristic for keeping a given control, and the SW torque level in parking condition. By satisfying the general requirements of these three aspects, the torque ratio for SBW system, which is based on negative equivalent assist torque characteristic, improves road feel and the on-center aligning performance achieves the target goals and provides a better handling and stability in different working conditions. Converting the study of the torque ratio into the study of the equivalent assist torque characteristic helps to make better use of current research results of the equivalent assist torque characteristic and promote the research of the torque ratio of SBW system. Simulation and vehicle test results show that the SW torque characteristic obtained is very similar to that of the reference vehicle.

\section{Conflict of Interests}

The authors declare that there is no conflict of interests regarding the publication of this paper.

\section{Acknowledgments}

This research was supported by Foundation of State Key Laboratory of Automotive Simulation and Control (no. 20120111) and the National High Technology Research and Development Program of China (863 Program) (no. 2012AA110904).

\section{References}

[1] J.-S. Im, F. Ozaki, N. Matsunaga, and S. Kawaji, "Bilateral control for steer-by-wire vehicles," in Proceedings of the SICE-ICASE International Joint Conference, pp. 528-533, Busan, Republic of Korea, October 2006. 
[2] S. Asai, H. Kuroyanagi, S. Takeuchi, T. Takahashi, and S. Ogawa, "Development of a steer-by-wire system with force feedback using a disturbance observer," SAE Technical Paper 2004-011100, 2004.

[3] Y. Yokokohji and T. Yoshikawa, "Bilateral control of masterslave manipulators for ideal kinesthetic coupling - formulation and experiment," IEEE Transactions on Robotics and Automation, vol. 10, no. 5, pp. 605-619, 1994.

[4] C. Jeffrey, R. Cutajar, A. Richardson, S. Prosser, M. Lickess, and S. Riches, "The integration of on-line monitoring and reconfiguration functions into a safety critical automotive electronic control unit," Journal of Electronic Testing: Theory and Applications, vol. 21, no. 4, pp. 405-416, 2005.

[5] S. Oh, S. Yun, H. Chae et al., "The development of an advanced control method for the steer-by-wire system to improve the vehicle maneuverability and stability," SAE Technical Paper, 2003.

[6] M. Kamel Salaani, G. J. Heydinger, and P. A. Grygier, "Experimental steering feel performance measures," SAE Technical Paper 2004-01-1074, 2004.

[7] H. Zheng, C. Zong, and L. Yu, "Road feel feedback design for vehicle steer-by-wire via electric power steering," SAE Technical Paper 2013-01-2898, 2013.

[8] E. Mehdizadeh, M. Kabganian, and R. Kazemi, "A new force feedback for Steer-by-Wire vehicles via virtual vehicle concept," in Proceedings of the 50th IEEE Conference on Decision and Control and European Control Conference, pp. 2281-2286, December 2011.

[9] U. B. Mandhata, M. J. Jensen, J. R. Wagner, F. S. Switzer, D. M. Dawson, and J. D. Summers, "Evaluation of a customizable haptic feedback system for ground vehicle steer-by-wire interfaces," in Proceedings of the American Control Conference (ACC '12), pp. 2781-2787, Montreal, Canada, June 2012.

[10] M. T. Do, Z. Man, C. Zhang, H. Wang, and F. S. Tay, "Robust sliding mode-based learning control for steer-by-wire systems in modern vehicles," IEEE Transactions on Vehicular Technology, vol. 63, no. 2, pp. 580-590, 2014.

[11] S. S. Saab and R. A. Kaed-Bey, "Parameter identification of a DC motor: an experimental approach," in Proceedings of the 8th IEEE International Conference on Electronics, Circuits and Systems (ICECS '01), vol. 2, pp. 981-984, September 2001.

[12] X. Wang, Research on bilateral control and variable ratio characteristics for steer-by-wire automobile [Ph.D. thesis], Jilin University, Changchun, China, 2013.

[13] X. Wang, C. Zong, H. Xing, R. Hu, and X. Xie, "Bilateral control method of torque drive/angle feedback used for steer-by-wire system," SAE Technical Paper 2012-01-0792, 2012.

[14] X. Na, Study on passenger cars handling objective benchmark targets setting [M.S. thesis], Jilin University, Changchun, China, 2009.

[15] C. Wang, Study on objective evaluation index system of oncenter handling for passenger car [M.S. thesis], Jilin University, Changchun, China, 2012.

[16] ISO 13674-1:2003, Road Vehicles-Test Method for The Quantification of On-Center Handling-Part1: Weave Test, ISO, 2003.

[17] G. P. Bertollini and R. M. Hogan, "Applying driving simulator to quantify steering effort preference as a function of vehicle speed," SAE Technical Paper 1999-01-0394, 1999.

[18] C. Zong, X. Na, and D. Hu, "Study on steering effort preference of drivers based on driving simulator," SAE Technical Paper 2007-01-3575, 2007.
[19] Y. W. Chai, "A study of effect of steering gain and steering torque on driver's feeling for SBW vehicle," in Proceedings of the FISITA World Automotive Congress, Barcelona, Spain, 2004.

[20] JASO C 705-72, Static Steering Efforts Test Procedure, JASO, Japan, 2004.

[21] B. Heissing and J. H. Brandl, Subjektive Beurteilung des Fahrverhaltens, Vogel Business Media, 2002.

[22] C. Zong, L. Mai, D. Wang, and Y. Li, "Study on steering effort preference of drivers based on driving simulator," Chinese Journal of Mechanical, vol. 18, no. 8, pp. 1001-1005, 2007.

[23] T. Kifuku and S. Wada, An Electric Power-Steering System, Mitsubishi Electric Advance, 1997.

[24] S. Rongwei, L. Yi, T. Xiaohong, and S. Guobiao, "Research on modeling and compensation control strategy of electric power steering system," Transactions of the Chinese Society of Agricultural Machinery, vol. 38, no. 7, pp. 5-9, 2007.

[25] W. Wang, Automobile Design, China Machine Press, Beijing, China, 2004. 


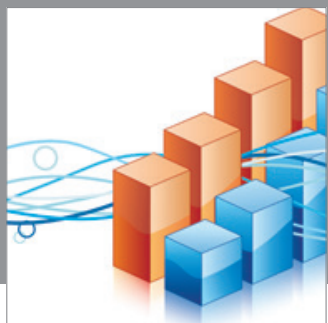

Advances in

Operations Research

mansans

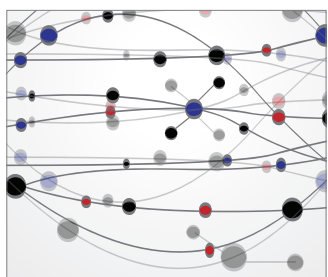

The Scientific World Journal
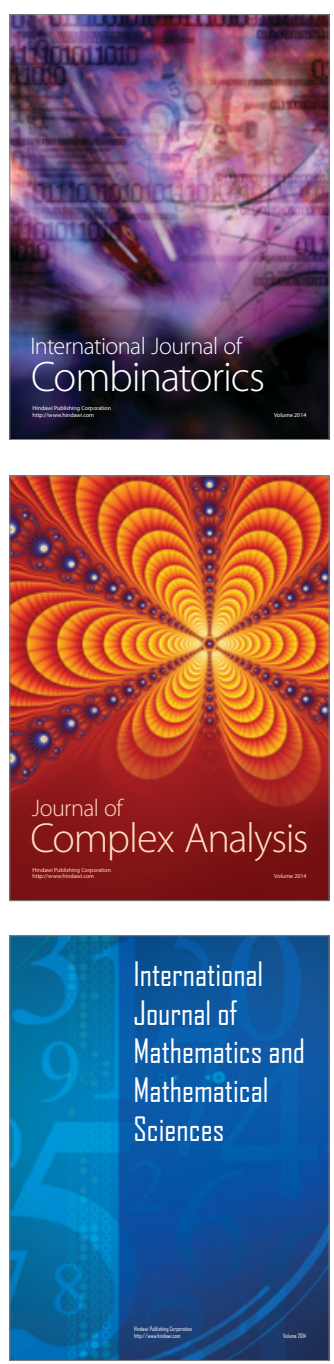
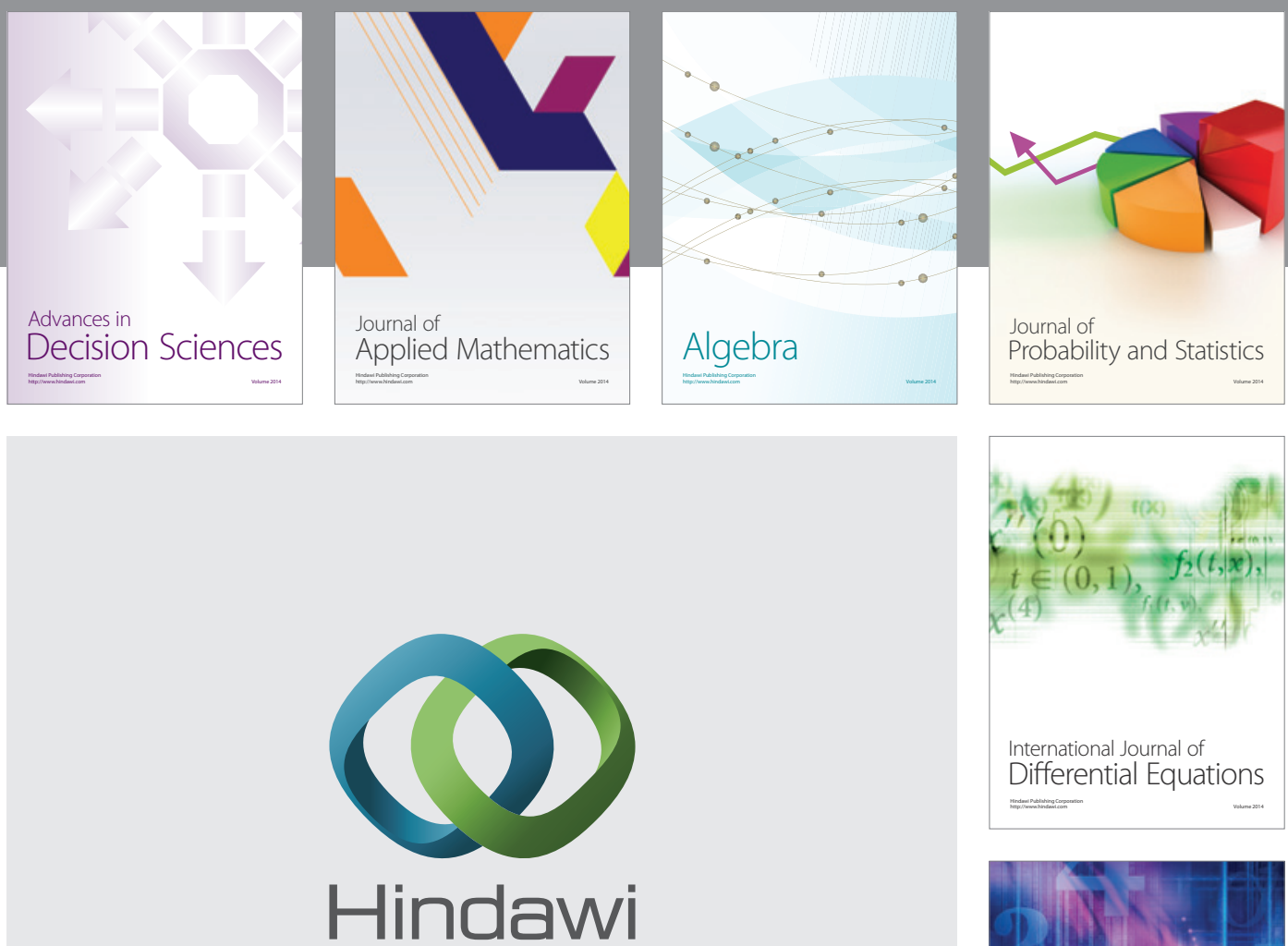

Submit your manuscripts at http://www.hindawi.com
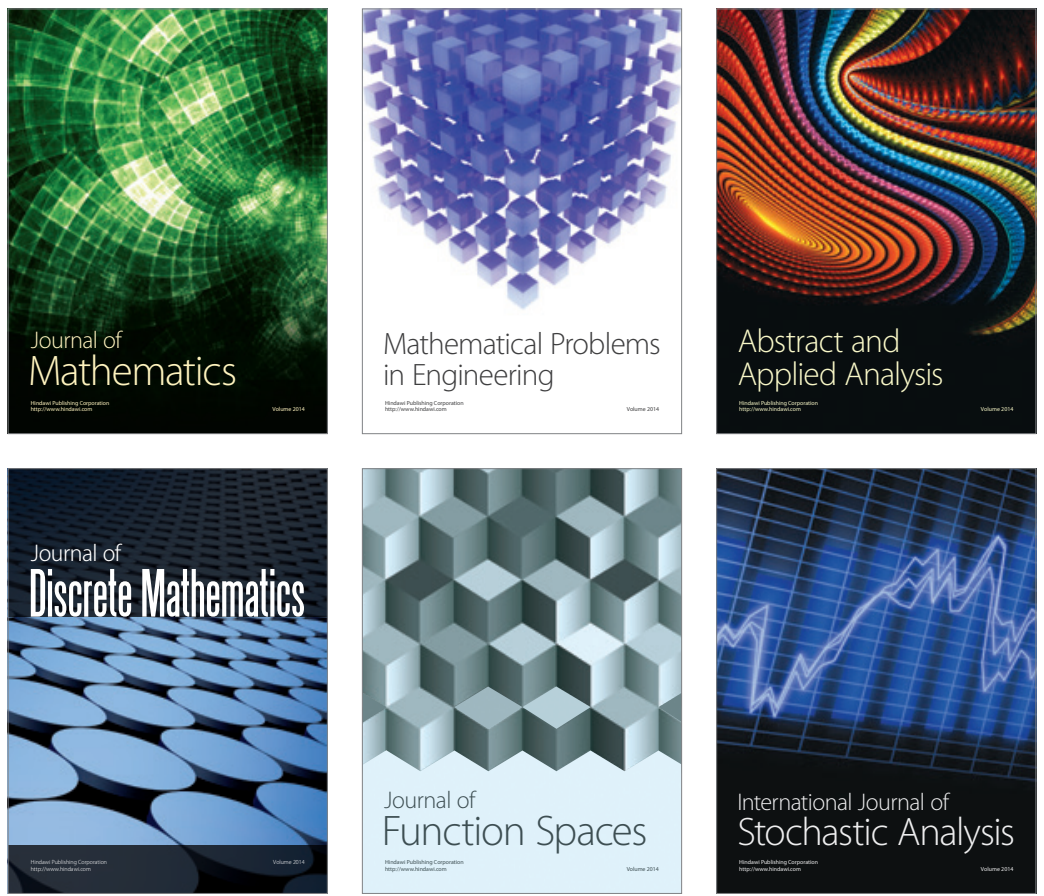

Journal of

Function Spaces

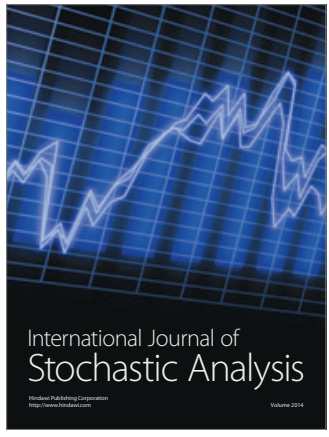

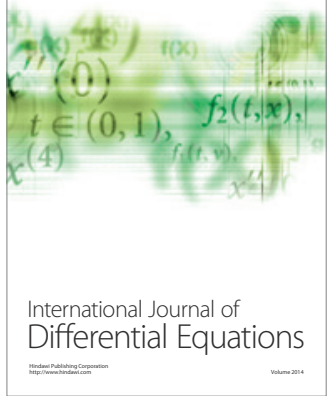
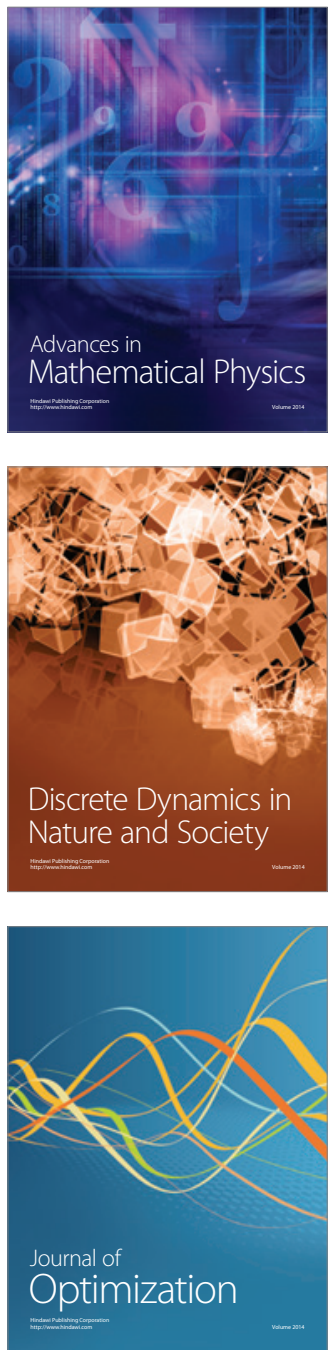